\title{
Effects of Different Administration Protocols on the Plasma Concentration of Donepezil Hydrochloride in Dementia Patients with Stage 5 Chronic Kidney Disease
}

\author{
Chika Amano ${ }^{a}$ b Takafumi Ito $^{a}$ Masahiro Egawa ${ }^{a}$ Tomohiro Oka ${ }^{a}$ \\ Ken Hanada $^{a}$ Kosuke Matsui ${ }^{a}$ Toru Nabika ${ }^{b}$ Kazuaki Tanabe ${ }^{c}$ \\ a Department of Nephrology, Shimane University Hospital, and ${ }^{b}$ Department of Functional \\ Pathology and ${ }^{\mathrm{C}}$ The 4th Department of Internal Medicine, Shimane University Faculty of \\ Medicine, Izumo, Japan
}

\author{
Key Words \\ Chronic kidney disease $\cdot$ Alzheimer's disease $\cdot$ Donepezil hydrochloride
}

\begin{abstract}
The prevalence of chronic kidney disease (CKD) as well as Alzheimer's disease (AD) increases with age. With the aging of the population in Japan, there is an increasing likelihood that patients with CKD will receive donepezil hydrochloride (DPZ), an antidementia drug, in the near future. Nevertheless, there have been few reports on how to use DPZ in patients with severe CKD. We report on 2 CKD stage 5 patients who received DPZ under different prescriptions. In case $1,3 \mathrm{mg} /$ day of DPZ was initially administered for 4 months, after which the dose was increased to $5 \mathrm{mg} /$ day. In case $2,5 \mathrm{mg}$ was administered twice a week. The plasma concentration of DPZ was measured and the effectiveness was assessed using the Mini-Mental Health State Examination and the Hasegawa Dementia Rating Scale. We found that (1) only a slight increase in the plasma concentration of DPZ was observed with a dose of $3 \mathrm{mg}$ daily, (2) there was a significant increase in the plasma concentration with a dose of $5 \mathrm{mg}$ daily, and (3) when $5 \mathrm{mg}$ of DPZ was administered twice a week, the plasma concentration did not differ significantly from healthy controls who had received $5 \mathrm{mg}$ daily. Although cognitive function was improved best when the 5 -mg dose was administered daily with no apparent side effects, the plasma concentration came close to reaching a toxic level at this dose. Careful follow-up may be essential when DPZ is used at $5 \mathrm{mg} /$ day or greater in severe CKD patients.
\end{abstract}


Amano et al.: Effects of Different Administration Protocols on the Plasma Concentration of Donepezil Hydrochloride in Dementia Patients with Stage 5 Chronic Kidney Disease

\section{Introduction}

Alzheimer's disease (AD) develops in the latter part of life. It is a degenerative disease of the brain characterized by early symptoms of memory loss and behavioral changes, which progresses to speech disorder and motor dysfunction. Although the pathogenic mechanism has not been elucidated yet, the level of acetylcholine in the brain has been found to decrease in $\mathrm{AD}$ patients, which might be important in the pathogenesis and progression of this disease $[1,2]$. Donepezil hydrochloride (DPZ), an acetylcholinesterase (AChE) inhibitor, has been shown to prevent the progression of AD symptoms, probably through increasing the acetylcholine level in the brain [3]. In addition, it has recently been suggested that DPZ reduces $\beta$-amyloid plaque in vitro, which might contribute to its anti-AD effects [4]. At present, DPZ remains one of the most popular and promising drugs for $\mathrm{AD}$.

The prevalence of chronic kidney disease (CKD) increases with advancing age [5]. An association was reported between impaired renal function and a rapid decline in cognitive function in elderly people [5]. Due to the rapid aging in Japan, we may have more opputunities to use DPZ in patients with both AD and CKD.

DPZ is eliminated through the kidney. The side effects of DPZ are commonly digestive symptoms. There are also other severe side effects such as delirium and gastrointestinal hemorrhage, and the plasma concentration should be carefully controlled in patients with reduced renal function. We report on $2 \mathrm{AD}$ patients with stage 5 CKD who received DPZ. Plasma concentrations and effectiveness were evaluated in relation to the dose of DPZ in these patients.

\section{Case Reports}

\section{Case 1}

The patient was an 80-year-old man with nephrosclerosis and drug-induced renal injury due to chemotherapy for lung cancer. The serum creatinine (Cr) level increased gradually from 1996, but it was still around $1 \mathrm{mg} / \mathrm{dl}$ in 1999 when he started treatment for hypertension. The serum $\mathrm{Cr}$ level was over $2 \mathrm{mg} / \mathrm{dl}$ in 2003. In 2008, the serum $\mathrm{Cr}$ reached 4.89 $\mathrm{mg} / \mathrm{dl}$, and he was seen at Shimane University Hospital. At admission, the estimated glomerular filtration rate level was $8.72 \mathrm{ml} / \mathrm{min} / 1.73 \mathrm{~m}^{2}$ (CKD stage 5), and the 24-hour Cr clearance was $6.5-13.9 \mathrm{ml} / \mathrm{min}$.

A few years before admission, the patient had progressive loss of memory and activity. Plain cranial MRI showed prominent hippocampal and cerebrocortical atrophy, as well as asymptomatic cerebral infarction. He was diagnosed with AD and began receiving DPZ (3 mg/ day). Since the symptoms did not improve much, the daily dose was increased to $5 \mathrm{mg}$ after 4 months of treatment.

The plasma concentration of DPZ was monitored on the 7th day of treatment ( $3 \mathrm{mg} /$ day) because it was considered to be stable after this period [according to the drug information (DI)]. The plasma concentration under the administration of $5 \mathrm{mg} /$ day was measured 8 months after the dose had been changed when the patient received an operation to construct an internal shunt for dialysis.

The plasma concentration was measured at $0,1,2,3,4,6,9$, 12, and $24 \mathrm{~h}$ after DPZ administration by high-performance liquid chromatography. The concentration was compared with the concentrations in healthy volunteers described in the DI because the plasma concentration of DPZ was not measured in individuals with normal renal function in the present study. Figure 1 shows changes in the renal function, Mini-Mental Health State Examination (MMSE), and Hasegawa Dementia Rating Scale (HDR-S) of case 1 over time. An improvement 


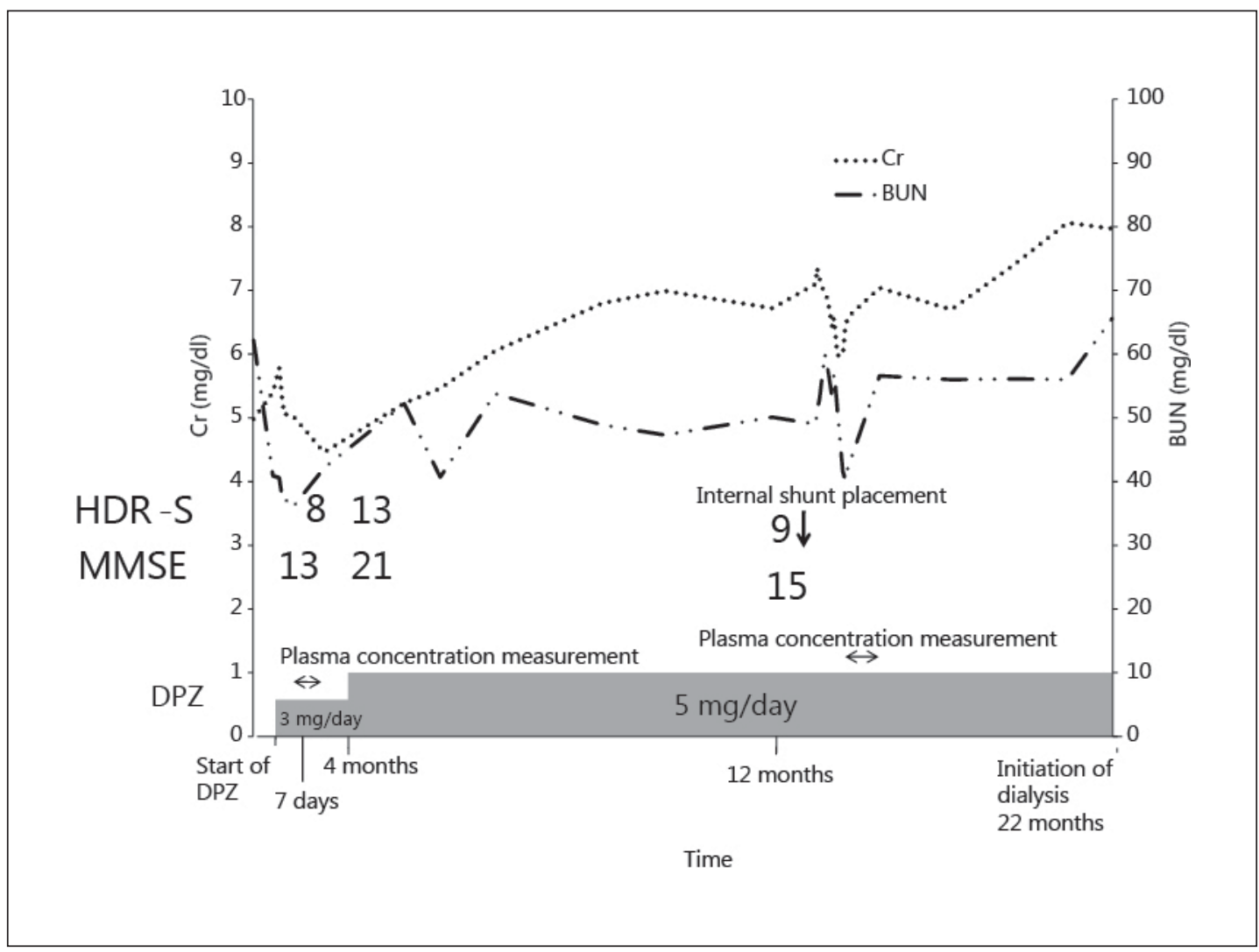

Fig. 1. Changes in the renal function, MMSE, and HDR-S scores over time in case 1. The dose was increased to $5 \mathrm{mg} /$ day 4 months after the start of DPZ administration because no apparent effects were observed with $3 \mathrm{mg} /$ day. An improvement in the MMSE and HDR-S scores was observed after 4 months of DPZ $5 \mathrm{mg} /$ day. When the renal function declined 1 year after the start of treatment, the MMSE score decreased slightly, while the HDR-S remained unchanged. BUN = Blood urea nitrogen.

in the MMSE and HDR-S scores was observed after 4 months of DPZ $5 \mathrm{mg} /$ day. When renal function declined 1 year after the start of treatment, the MMSE score decreased slightly, while the HDR-S remained unchanged.

Figure 2 shows the change in the plasma concentration of DPZ administered at 3 and $5 \mathrm{mg} /$ day in case 1 . The trough level $(11.7 \mathrm{ng} / \mathrm{ml})$ with the $3-\mathrm{mg}$ daily dose in this patient was the same as the trough level $(10-15 \mathrm{ng} / \mathrm{ml})$ in healthy male adults with a 5-mg daily dose (according to the DI). No peak of the plasma concentration was prominent and there was only a slight increase in the overall plasma concentrations. The maximum plasma concentration $\left(\mathrm{C}_{\max }\right)$ was $44.2 \mathrm{ng} / \mathrm{ml}$ with the 5 -mg daily dose, which was considerably higher than the $\mathrm{C}_{\max }$ in the healthy volunteers (according to the DI). Further, the trough level $(28.68 \pm 5.21 \mathrm{ng} / \mathrm{ml})$ was almost the same as the $\mathrm{C}_{\max }$ in healthy male adults with $5 \mathrm{mg} /$ day $(29.8 \mathrm{ng} / \mathrm{ml}$ according to the DI). The time to reach the $\mathrm{C}_{\max }\left(\mathrm{t}_{\max }\right)$ was $1-2 \mathrm{~h}$ in this patient, which was almost the same as the $t_{\max }$ in healthy male adults with single-dose administration. The area under the plasma concentration-time curve (AUC) was $314.35 \mathrm{ng} \cdot \mathrm{h} / \mathrm{ml}$ with the $3-\mathrm{mg}$ daily dose and $849.35 \mathrm{ng} \cdot \mathrm{h} / \mathrm{ml}$ with the $5-\mathrm{mg}$ daily dose (table 1 ). No side effects were observed in this patient throughout the observed period. 


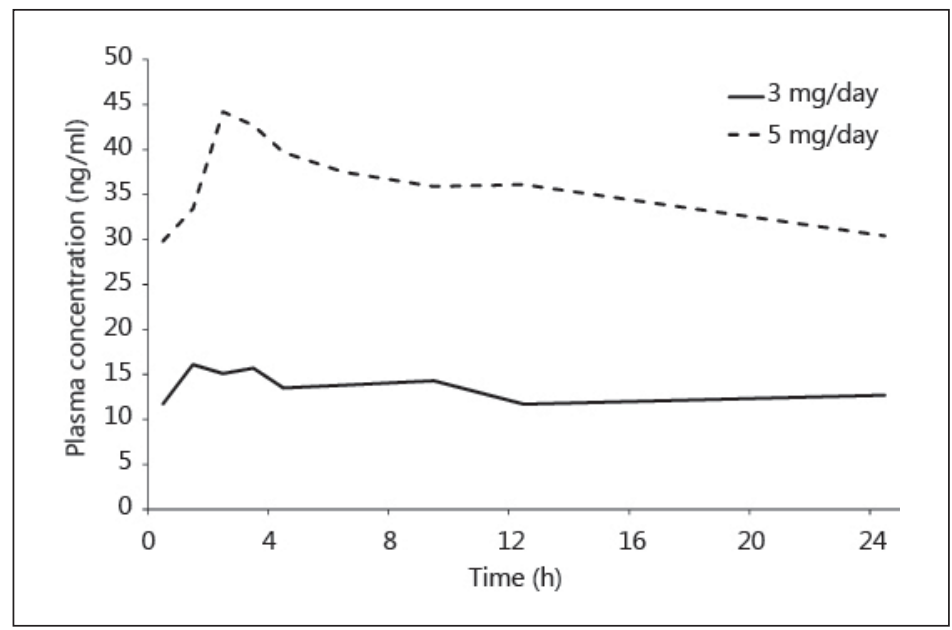

Fig. 2. Change in the plasma concentration of DPZ administered at 3 and $5 \mathrm{mg} /$ day in case 1 . The trough level $(11.7 \mathrm{ng} / \mathrm{ml})$ with the $3-\mathrm{mg}$ daily dose was the same as the trough level $(10-15 \mathrm{ng} / \mathrm{ml})$ in healthy male adults with a 5-mg daily dose (according to the DI). No peak of the plasma concentration was prominent and there was only a slight increase in the overall plasma concentrations. With the 5-mg daily dose, the $\mathrm{C}_{\max }$ was $44.2 \mathrm{ng} / \mathrm{ml}$, which was considerably higher than that in the healthy volunteers (according to the DI).

Table 1. Comparison of pharmacokinetic parameters

\begin{tabular}{|c|c|c|c|c|c|}
\hline & Trough level & $\begin{array}{l}\mathrm{C}_{\max } \\
\mathrm{ng} / \mathrm{ml}\end{array}$ & $\begin{array}{l}\mathrm{t}_{\max } \\
\mathrm{h}\end{array}$ & $\begin{array}{l}\text { AUC } \\
\mathrm{ng} \cdot \mathrm{h} / \mathrm{ml}\end{array}$ & $\begin{array}{l}\text { Estimated AUC } \\
(1 \text { week })^{b} \\
\mathrm{ng} \cdot \mathrm{h} / \mathrm{ml}\end{array}$ \\
\hline Case $1-1$ (3 mg/day) & 11.7 & 16.1 & $1 \pm 1$ & $314.35(24 \mathrm{~h})$ & $2,200.45$ \\
\hline Case $1-2$ (5 mg/day) & 29.8 & 44.2 & $2 \pm 1$ & $849.35(24 \mathrm{~h})$ & $5,945.45$ \\
\hline Case 2 (10 mg/week) & 9.1 & 30.7 & $2 \pm 1$ & $938.95(72 \mathrm{~h})$ & $2,096.3$ \\
\hline $\begin{array}{l}\text { Healthy male adult }{ }^{\mathrm{a}} \\
\qquad(5 \mathrm{mg} / \text { day } 14 \text { days })\end{array}$ & $\begin{array}{l}10-15 \\
\text { estimated from DI }\end{array}$ & $28.68 \pm 5.21$ & $2.4-4.7$ & $525.87 \pm 117.17(24 \mathrm{~h})$ & $3,681.09$ \\
\hline
\end{tabular}

${ }^{\text {a }}$ Medical supply interview form; Aricept ${ }^{\circledR}$.

${ }^{\mathrm{b}}$ Case 1: AUC (24 h) × 7; case 2: AUC (72 h) × 3 + AUC [24 h (3 day)].

Case 2

The patient was a 67-year-old man with chronic glomerulonephritis. He received a heminephrectomy due to renal tuberculosis in 1955. His renal function progressively deteriorated, and albuminuria and hematuria had been present since his $30 \mathrm{~s}$. He first visited our hospital in 1999, and over the years his blood urea nitrogen and serum $\mathrm{Cr}$ levels gradually increased. In 2008, his estimated glomerular filtration rate and 24-hour $\mathrm{Cr}$ clearance reached $7.1 \mathrm{ml} / \mathrm{min} / 1.73 \mathrm{~m}^{2}$ (CKD stage 5) and 11.2-15.4 ml/min, respectively. He was hospitalized for the preparation for hemodialysis.

The patient began to complain about forgetfulness and stumbling about 4 months before hospitalization. Plain cranial MRI showed prominent hippocampal and cerebrocortical atrophy, and he was diagnosed with AD. Administration of DPZ was started at a low dose of $1.5 \mathrm{mg} /$ day in consideration of his deteriorated renal function. As the serum $\mathrm{Cr}$ level was elevated after 2 weeks of treatment, the dose was changed to $3 \mathrm{mg}$ twice a week, and then finally to $5 \mathrm{mg}$ twice a week. His renal function has been stable since then. 


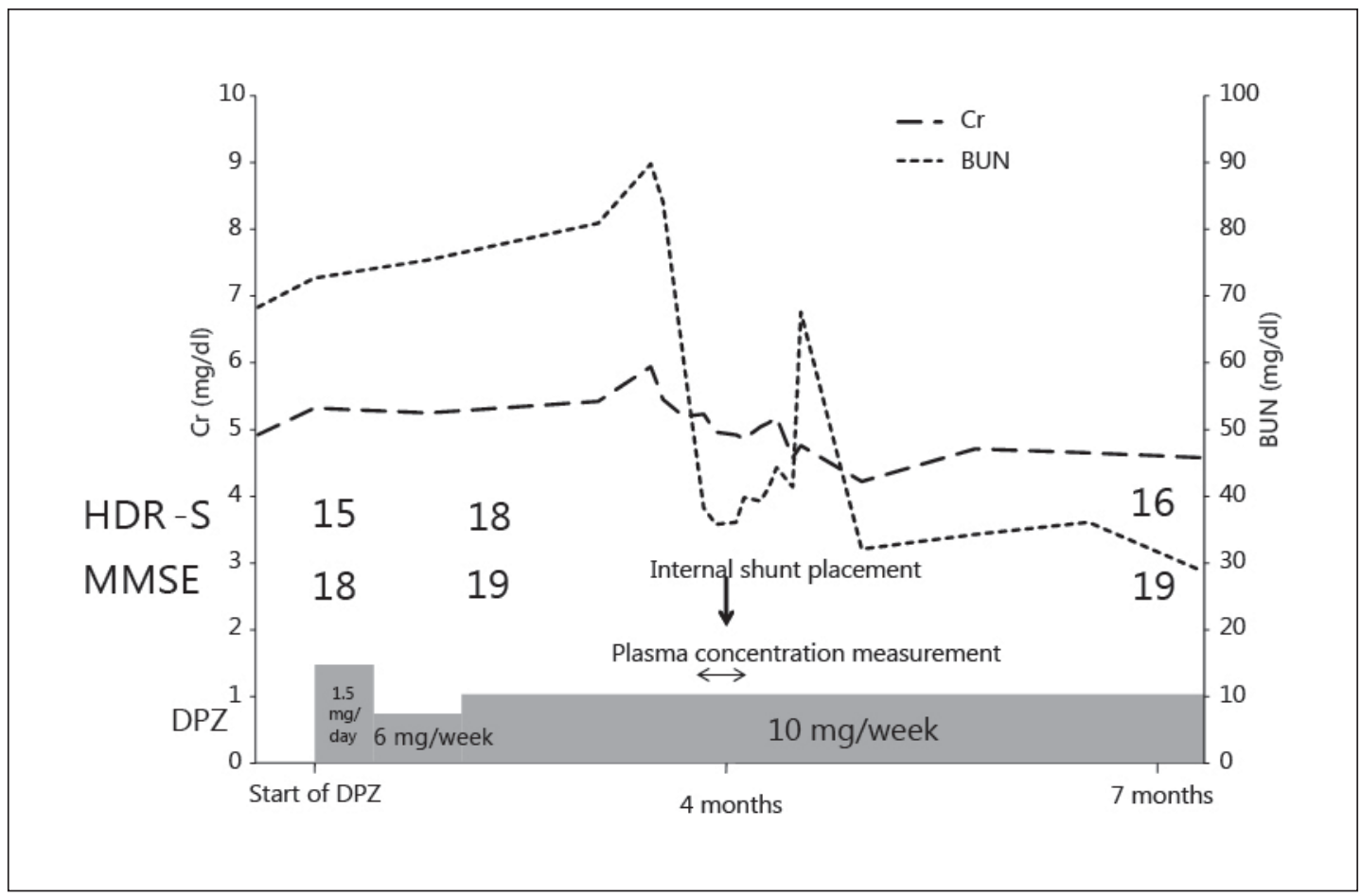

Fig. 3. Changes in the renal function, MMSE, and HDR-S scores over time in case 2. Overall, MMSE and HDR$\mathrm{S}$ scores remained almost unchanged 7 months after the start of the DPZ administration. BUN = Blood urea nitrogen.

Figure 3 shows changes in the renal function, MMSE, and HDR-S over time. Overall, MMSE and HDR-S scores remained almost unchanged 7 months after DPZ administration.

The plasma concentration was measured at $0,1,2,3,4,6,9,12,24,48$, and $72 \mathrm{~h}$ after the administration of $5 \mathrm{mg}$ of DPZ following about 4 months of treatment with DPZ (fig. 4). The trough level $(9.1 \mathrm{ng} / \mathrm{ml})$ with this dose was the same as or slightly lower than the trough level in healthy male adults with the 5 -mg daily dose $(10-15 \mathrm{ng} / \mathrm{ml})$. The change in the plasma concentration in the initial $24 \mathrm{~h}$ was similar to that in healthy male adults with $5 \mathrm{mg} /$ day. However, since this patient received DPZ twice a week, it was not reasonable to compare the $\mathrm{C}_{\max }$ in this patient with the $\mathrm{C}_{\max }$ in the DI according to which volunteers received daily administration. The AUC for 7 days was $3,681.09 \mathrm{ng} \cdot \mathrm{h} / \mathrm{ml}$ in healthy male adults with the $5-\mathrm{mg}$ daily dose, while the AUC was 2,096.3 $\mathrm{ng} \cdot \mathrm{h} / \mathrm{ml}$ in this patient with the $5-\mathrm{mg}$ dose twice a week. As the plasma concentration in this patient had only two peaks a week, the AUC per week was expected to be lower than that under daily administration. The $t_{\max }$ was $1-2 \mathrm{~h}$ for this patient, which was almost the same as the $t_{\max }$ in healthy male adults with single-dose administration (table 1). No side effects were observed in this patient throughout the observed period.

\section{Discussion}

Reduced levels of acetylcholine in the brain have been implied to be a key target in the treatment of AD $[1,2]$. DPZ is known to inhibit AChE and to delay the progression of AD symptoms [3]. The effective plasma concentration of DPZ has been reported to be $10-20 \mathrm{ng} /$ $\mathrm{ml}$, but there are no reliable data available on the optimum dose [6]. 


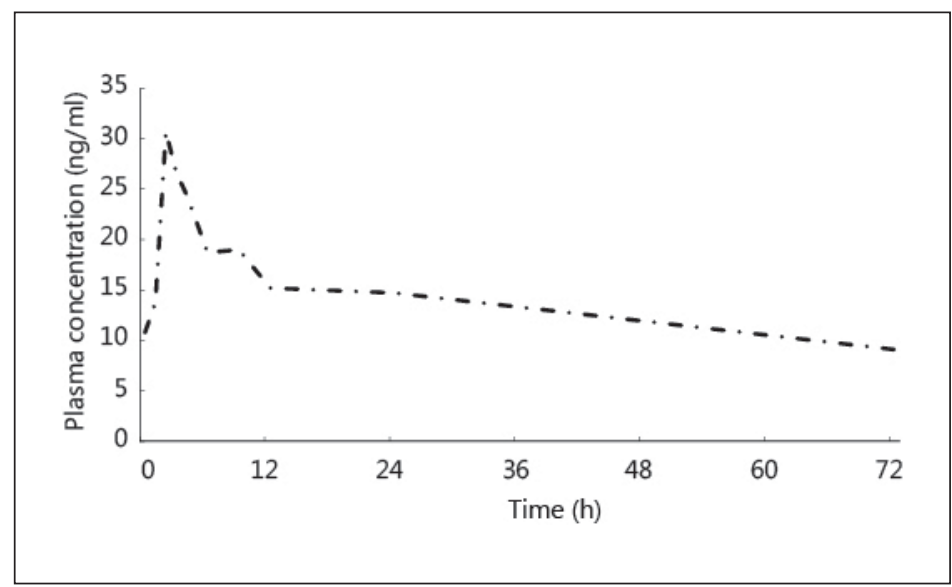

Fig. 4. Change in the plasma concentration of DPZ administered at $10 \mathrm{mg} /$ week in case 2 . The plasma concentration was measured just before the construction of an internal shunt for dialysis. The trough level ( 9.1 $\mathrm{ng} / \mathrm{ml}$ ) was the same as or slightly lower than the trough level in healthy male adults receiving the 5-mg daily dose (10-15 $\mathrm{ng} / \mathrm{ml})$. The change in the plasma concentration in the initial $24 \mathrm{~h}$ was similar to that in the healthy male adults with the 5-mg daily dose. However, since the patient received DPZ twice a week, it was not reasonable to compare the $\mathrm{C}_{\max }$ in this patient with the $\mathrm{C}_{\max }$ in the DI according to which volunteers received daily administration.

As DPZ is eliminated through the kidney, the plasma concentration is expected to increase in patients with impaired renal function. In contrast to this expectation, Tiseo et al. [7] found no significant difference in DPZ plasma concentrations between subjects with impaired renal function and normal subjects [8]. In their report, however, the 24-hour Cr clearance in the 11 patients studied ranged from 7.3 to $30 \mathrm{ml} / \mathrm{min} / 1.73 \mathrm{~m}^{2}$, including some with better renal function when compared with the patients in the present study. In addition, using a single administration, they observed that the $\mathrm{C}_{\max }$ in some patients with lower renal function tended to be greater than the $\mathrm{C}_{\max }$ in normal controls. In light of these observations and consistent with our own findings, we need to be cautious when DPZ is administered to patients with severe CKD.

We observed that the DPZ plasma concentration $24 \mathrm{~h}$ after administration was slightly higher than that at $0 \mathrm{~h}$. This implies that an unexpected increase in the plasma concentration is possible when DPZ is administered daily. Although no side effects were observed even with the daily administration of $5 \mathrm{mg}$ in case 1 , we should still be cautious because further reduction in the renal function may cause a sudden manifestation of severe side effects of DPZ. Supporting this concern, the trough level in case 1 with DPZ $5 \mathrm{mg}$ /day was higher than the $\mathrm{C}_{\max }$ in the healthy male adults using the same dose. Rogers et al. [9] reported that a plasma concentration of $50 \mathrm{ng} / \mathrm{ml}$ or greater reduced the AChE activity by $80-90 \%$, which might be quite effective in treatment. However, Yano et al. [6] reported a case which experienced toxic effects from DPZ at $54.6 \mathrm{ng} / \mathrm{ml}$. They also reported that the toxic effects disappeared when the concentration was reduced to $47.3 \mathrm{ng} / \mathrm{ml}$, suggesting that a plasma concentration of around $50 \mathrm{ng} / \mathrm{ml}$ is critical for the toxic effects of DPZ. The fact that the $\mathrm{C}_{\max }$ reached close to this level in case 1 with the 5-mg daily administration of DPZ may indicate that higher daily doses of DPZ to patients with severe CKD require extreme caution.

Rogers et al. [9] reported that the $\mathrm{EC}_{50}$ (the concentration at which $50 \%$ of AChE activity is inhibited) in their study was $15.6 \mathrm{ng} / \mathrm{ml}$. Examining the 2 cases in the present report, case 1 showed improvement in MMSE and HDR-S after DPZ administration was started. Based on 
Amano et al.: Effects of Different Administration Protocols on the Plasma Concentration of Donepezil Hydrochloride in Dementia Patients with Stage 5 Chronic Kidney Disease

this result, it may be recommended to maintain the plasma concentration of DPZ at 15-50 $\mathrm{ng} / \mathrm{ml}$.

According to Tom Kitwood's theory, changes in cognitive function are influenced strongly by factors such as the environment [10]. Therefore, to evaluate the net effect of DPZ on cognitive function, it is necessary to examine how cognitive functions change under a fixed optimized plasma concentration of the drug.

\section{References}

1 Coyle JT, Price DL, DeLong MR: Alzheimer's disease: a disorder of cortical cholinergic innervation. Science 1983;219:1184-1190.

-2 Reinikainen KJ, Soininen H, Riekkinen PJ: Neurotransmitter changes in Alzheimer's disease: implications to diagnostics and therapy. J Neurosci Res 1990;27:576-586.

-3 Sugimoto H: Donepezil hydrochloride: a treatment drug for Alzheimer's disease. Chem Rec 2001;1: 63-73.

-4 Sugimoto H: The new approach in development of anti-Alzheimer's disease drugs via the cholinergic hypothesis. Chem Biol Interact 2008;175:204-208.

5 Buchman AS, Tanne D, Boyle PA, Shah RC, Leurgans SE, Bennett DA: Kidney function is associated with the rate of cognitive decline in the elderly. Neurology 2009;73:920-927.

-6 Yano H, Fukuhara Y, Wada K, Kowa H, Nakashima K: A case of acute cholinergic adverse effects induced by donepezil overdose: a follow-up of clinical course and plasma concentration of donepezil (in Japanese). Rinsho Shinkeigaku 2003;43:482-486.

-7 Tiseo PJ, Foley K, Friedhoff LT: An evaluation of the pharmacokinetics of donepezil $\mathrm{HCl}$ in patients with moderately to severely impaired renal function. Br J Clin Pharmacol 1998;46(suppl 1):56-60.

8 Nagy CF, Kumar D, Cullen EI, Bolton WK, Marbury TC, Gutierrez MJ, Hutman HW, Pratt RD: Steady-state pharmacokinetics and safety of donepezil $\mathrm{HCl}$ in subjects with moderately impaired renal function. Br J Clin Pharmacol 2004;58(suppl 1):18-24.

-9 Rogers SL, Doody RS, Mohs RC, Friedhoff LT: Donepezil improves cognition and global function in Alzheimer disease: a 15-week, double-blind, placebo-controlled study. Donepezil Study Group. Arch Intern Med 1998; 158:1021-1031.

10 Kitwood T, Bredin K: Towards a theory of dementia care: personhood and well-being. Ageing Soc 1992;12: 269-287. 